\title{
EKSISTENSI DAN KEBERLANJUTAN KAMPUNG JOGLO DALAM MASYARAKAT, BUDAYA DAN LINGKUNGAN ASLINYA
}

\author{
Baju Arie Wibawa \\ Program Studi Arsitektur, Fakultas Teknik dan Informatika UPGRIS \\ bayu.ariwibawa@gmail.com \\ Kurnia Widiastutui \\ Program Studi Arsitektur, Fakultas Teknik dan Informatika UPGRIS \\ Widya_unlam@yahoo.com \\ Velma Nindita \\ Program Studi Arsitektur, Fakultas Teknik dan Informatika UPGRIS \\ Velma_nindita@yahoo.com
}

\begin{abstract}
Abstrak
Joglo merupakan arsitektur tradisional sebagai representasi budaya Jawa terpopuler. Hambatan utama adalah pada aspek keberlanjutannya dalam menghadapi pengaruh global. Akibatnya, eksistensinya di masa mendatang hanya akan tertinggal pada "museum" yang terlepas dari masyarakat/budaya aslinya. Kampung Joglo di Pondokrejo ini sangat unik (anomali) karena ekesitensi rumah joglo masih sangat banyak dan tetap tumbuh. Penelitian ini mendata eksistensi rumah-rumah joglo yang ada serta menganalisis pada empat pilar keberlanjutan (sosial, ekonomi, lingkungan dan budaya). Pendekatan kualitatif dilakukan pada tahap pendataan dan analisis bangunan, serta dilanjutkan kualitatif melalui wawancara mendalam untuk menganalisis keberlanjutannya. Hasil penelitian ini menunjukkan bahwa eksistensi dan jumlah rumah joglo masih sangat banyak dan tetap bertambah dari tahun ke tahun. Semua pilar keberlanjutan adalah terlihat dan jelas dalam lingkungan ini, sehingga dapat menjelaskan eksistensi dan berkelanjutannya.
\end{abstract}

Kata kunci:Joglo,vernakular, tradisional, Jawa, Pondokrejo.

\begin{abstract}
Joglo is a traditional architecture as a representation of the most popular Javanese culture. The main obstacle is the aspect of sustainability in facing global influences. As a result, its existence in the future will only be left behind in the "museum" which is independent of its original community/culture. Joglo village in Pondokrejo is unique (anomaly) because the joglo house is still very much in existence and still growing. This research records the presence of existing joglo houses and analyzes the four pillars of sustainability (social, economic, environmental and cultural). The qualitative approach was carried out at the data collection and building analysis stage and continued qualitatively through in-depth interviews to analyze its sustainability. The results of the study show that the existence and number of joglo houses are still significant and continues to convert from year to year. All pillars of sustainability are present and clear in this environment so that they can explain their existence and sustainability.
\end{abstract}

Keywords: Joglo, vernacular, traditional, Jawa, Pondokrejo. 


\section{PENDAHULUAN}

Arsitekturtradisionalnusantarakebera daannya telah terbukti dan adaptif pada kondisi alam setempat, serta dipadukan dengan budaya lokal setempat(Susilo, 2010). Bangunan berbentuk Joglo adalah arsitektur tradisional yang dikenal sebagai representasi budaya Jawa merupakan perwujudan ruang hidup fisik budaya Jawa yang terpopuler (Pitana, 2013). Walaupun Joglo bukan satu-satunya bentuk arsitektur Jawa, namun bentuknya sudah menjadi citra atau simbol budaya Jawa selain bentuk tajuk, dengan semua variasi perkembangannya (Wibawa, 2018).

Dalam eksistensinya, bangunan berbentuk joglo seringkali menghadapi kendala pada beberapa aspek seperti sulitnya mendapat kayu jati, harga kayu yang tinggi, keterbatasan bentang struktur, umur kayu yang terbatas, dan lain-lain. Beragam kendala ini membuatbangunan joglo(khususnya rumah tinggal)seringkali tidak mampu untuk bersaing dengan rumah moderndengan semua kelebihannya. Keyataan inimenunjukkan bahwa eksistensi arsitektur Joglo sangat terikat pada masa lalu serta dinilai tidak kampung,limasan atau panggangpe

mampu mengikuti perkembangan global(Pitana, 2013).

Bentuk bangunan joglo dengan semua makna simbolis serta harga tinggi yang dimilikinyamenjadikan eksistensi dan keberlanjutan pembangunannya menghadapi berbagai kendala, akibatnya bentuk joglo seringkali hanya dipakai pada bangunan-bangunan umum atau publik seperti pendopo, balai pertemuan, kantor, dll.). Permasalahan ini menjadikan bangunan joglo sulit untuk bertahan atau berkelanjutandalam menghadapi perkembangan global. Kecenderungan ini mengakibatkan kelestarian dan eksitensi bangunan rumah joglo pada setting lingkungan aslinya menjadi semakin berkurang. Sekarang sudah sulit untuk dapat menemukan rumah joglo asli yang dapat lestari dalam setting budaya dan sosial asli penduduknya serta dalam setting lingkungan aslinya. Rumah tinggal Joglo telah sulit ditemukan pertumbuhannya, terdapat kemungkinan di masa mendatang bahwa kita hanya akan dapat melihat fisik rumah joglo (container) hanya pada museum atau maket yang pasti telah terlepas masyarakatnya (content) serta lokasinya sudah terjabut

\section{Gambar 1.}

Bentang alam Kampung Joglo Pondokrejo

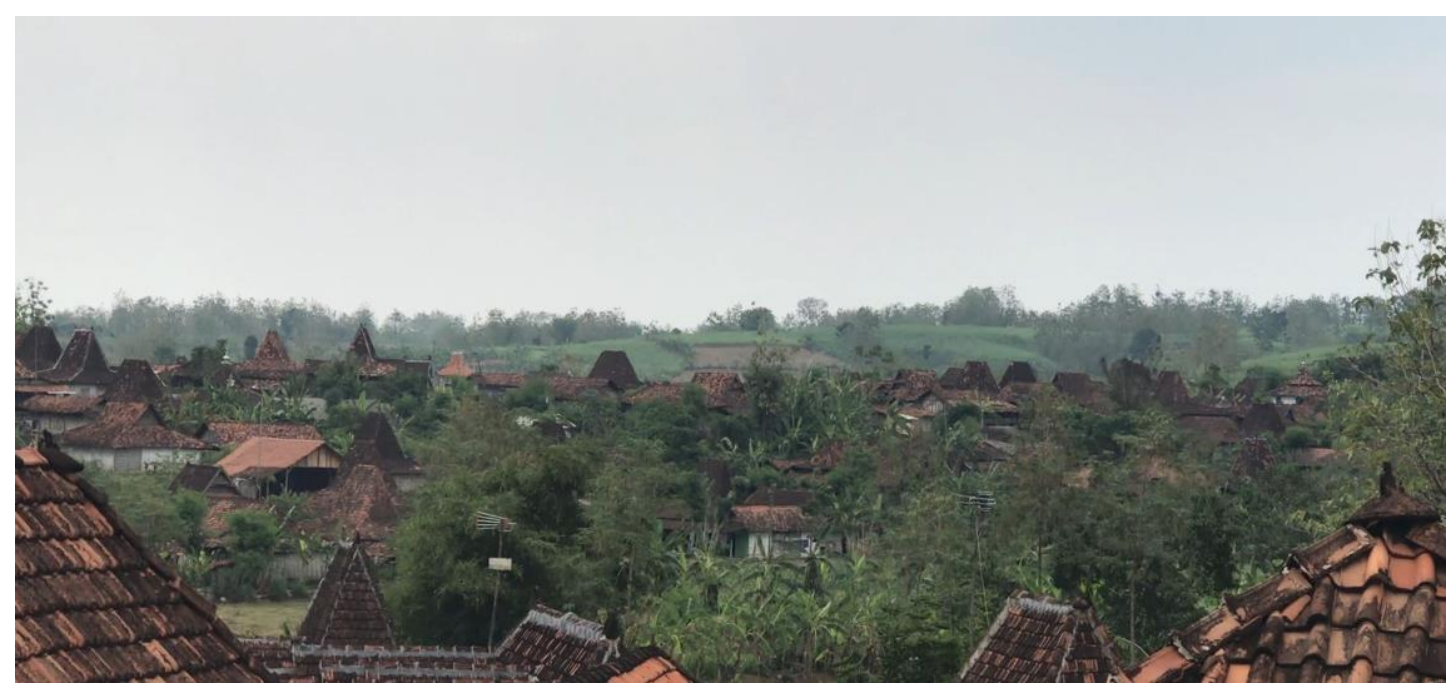


daricontext lingkungan alam aslinya(Wibawa, 2018).

Adanya fenomena keberadaan rumah joglo tidak bertambah dan bahkan berkurang, ternyata tidak terjadi di Kampung Joglo yang berupa permukiman dengan bentuk utama rumah tinggal adalah joglo yang berada di Desa Pondokrejo, Kec. Bulu, Kab. Rembang. Ada satu anomali bahwa di kawasan permukiman tradisional ini jumlah rumah dengan bentuk joglo ternyata dapat bertahan dan malah menunjukkan adanya pertumbuhan dari tahun ke tahun. Bangunan rumahrumah joglo di desa ini masih dalam bentuk asli yang tetap bertahan dalam lingkungan masyarakat petani Jawa yang asli pula (lihat Gambar 1). Eksistensi lingkungan permukiman joglo ini adalah unik dan spesifik yang sampai sekarang masih mampu beradaptasi dan lestari menghadapi perkembangan global(Wibawa, 2018).

\section{METODE PENELITIAN}

Penelitian ini dilakukan dengan pendekatankuantitatif dan kualitatif yang dilakukan secara bertahap yang selanjutnya dianalisis secara deskriptif. Kegiatan awal adalah pengumpulan data dilakukan melalui pendataan bentuk dan jumlah rumah dilakukan secara kuantitatif untuk dapat mendeskripsikan jumlah dan tingkat pertumbuhan rumah joglo. Selanjutnya pendekatan kualitatif dilaksanakan melalui interview dan wawancara secara cukup mendalam dalam upaya untuk dapat memperoleh gambaran latar belakang budaya yang dapat membentuk eksistensi bangunan rumah joglo yang mereka bangun.

Analisis kualitatif dilakukan secara sederhana dengan analisis deskriptif (jumlah, rata-rata, modus, dll.). Analisis kualitatif dilakukan melalui kompilasi dan pengolahan beberapa sumber data wawancara dan pengamatan visual, sehingga diperoleh pengulangan

Gambar 2. Lokasi Kampung Joglo Pondokrejo

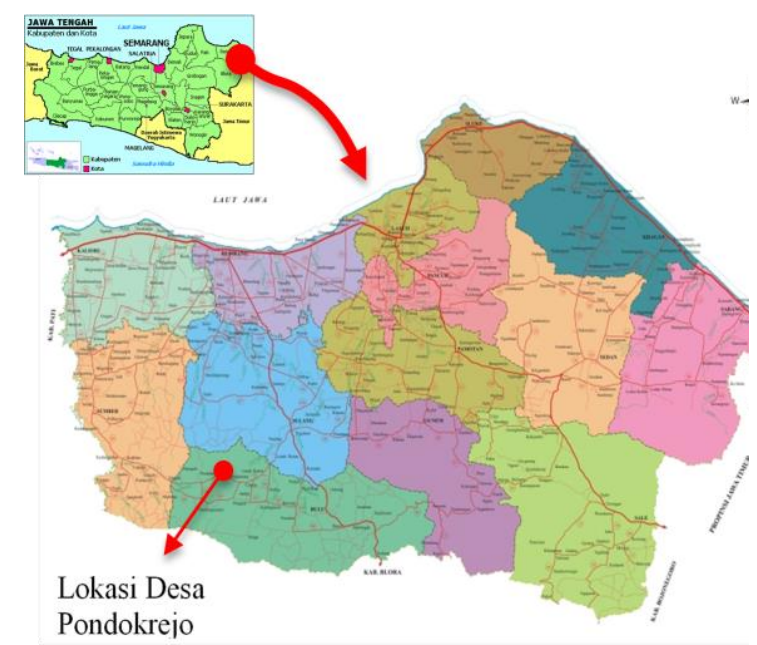

persamaan yang dinilai telah jenuh dan mewakili kondisi lapangan.

Analisis keberlanjutan dilakukan secara kualitatif deskriptif terhadap 4 pilar dalam pendekatan pembangunan yang keberlanjutan.

Obyek penelitian yang diteliti meliputi semua rumah-rumah tinggal yang ada di Desa Pondokrejo sebanyak 814 bangunan.

\section{HASIL DAN PEMBAHASAN}

\section{A. Lokasi Kampung Joglo}

Permukiman tradisional yang ada di Desa Pondokrejo merupakan lingkungan permukiman yang masih melestarikan rumah tinggal berbentuk Joglo. Letak permukiman joglo ini terletak di Desa Pondokrejo, Kecamatan Bulu, Kabupaten Rembang, Provinsi Jawa Tengah. Secara aksesbilitas lokasi permukiman ini memang tidak berada di jalur jalan regional/nasional, tapi cukup mudah untuk diakses dari jalan lingkar yang melalui ibukota Kecamatan Sulang, Sumber dan Kaliori. Jarak lokasi permukiman dari ibukota Kabupaten Rembang sejauh $+21 \mathrm{~km} \mathrm{ke}$ arah 
selatan.

\section{B. Sejarah Kampung Joglo}

Dari data data peta Belanda tahun 1928-1938 dapat terlihat bahwa pada saat itu sedikitnya terdapat 3 blok Pondo Londho yang berada di tengahtengah desa ini. Menurut para sesepuh, desa ini dahulu bernama Pondok Londo yang berarti "Rumah Belanda", karena saat itu terdapat orang-orang Belanda yang hidup lama dan membangun rumah-rumah besar dan disebut rumah joglo. Dalam perkembangannya setelah jaman republik, nama Pondok Londo dirubah menjadi Desa Pondokrejo(Wibawa, 2018).

\section{Analisis Kondisi Masyarakat}

Jumlah penduduk Desa Pondokrejo Gambar 3. Mata pencaharian masyarakat

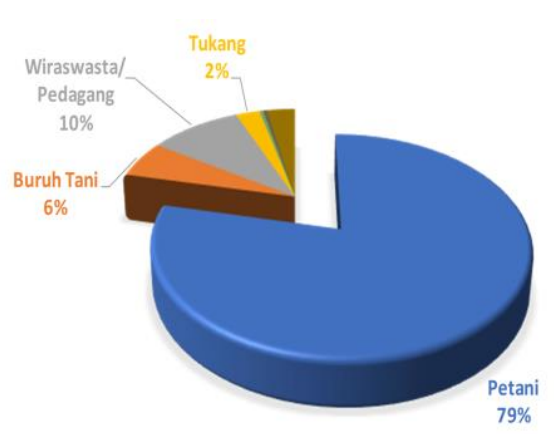

Sumber: Pendataan lapangan 2017

(2017)sebanyak 1.322 orangdalam 484 KK. Mata pencaharian terbesar sebagai petani (825 jiwa) dan buruh tani (60 jiwa).

Aktivitas utama bercocok tanam ini dapat dilihat dari kondisi alam yang ada, di mana sebagian besar lahan persawahan yang berada di dataran rendah dan permukiman di dataran atas. Kehidupan pedesaan agraris inilah yang menjadikan warga sangat menghormati alam dan menjaga tradisitradisi leluhur(Wibawa, 2018).

\section{Analisis Bentuk Rumah}

Ragam bentuk rumah yang ada di Kampung Joglo Pondokrejo adalah sebagai berikut:

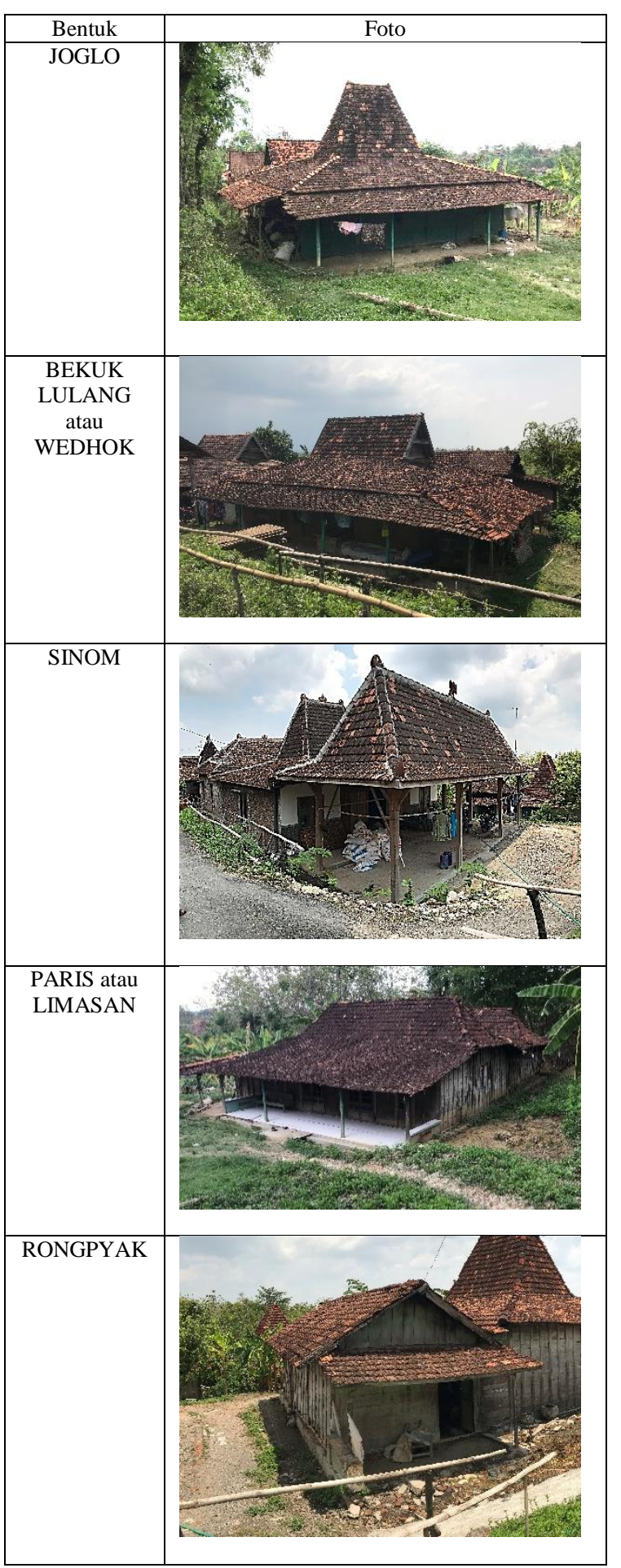




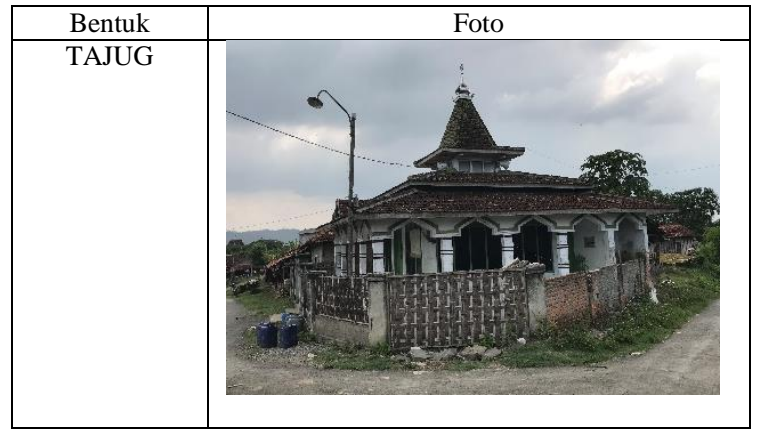

E. Analisis Jumlah Rumah Joglo

Gambar 4. Siteplan perkampungan jogo

Sumber: Pendataan lapangan 2018

Total jumlah bangunan rumah di Desa Pondokrejo adalah 814 rumah yang dimiliki 422 Kepala Keluarga (KK). Dari pendataan lengkap (2017) terdapat 229 rumah yang berbentuk Joglo $(47,3 \%)$ dari 422 keluarga yang ada.Jumlah ini merupakan angka yang fantastis hanya dalam satu lingkungan

Gambar 7.

Jumlah rumah menurut bentuknya

\begin{tabular}{|c|c|c|c|c|r|r}
\hline \multirow{2}{*}{ RT } & \multicolumn{7}{|c|}{ JENIS RUMAH } & \multirow{2}{*}{} \\
\cline { 2 - 7 } & JOGLO & $\begin{array}{c}\text { WEDOK/ } \\
\text { BEKUK } \\
\text { LULANG }\end{array}$ & SINOM & PARIS & RONGPYAK & JUMLAH \\
\hline 1 & 25 & 8 & 4 & 9 & 26 & 72 \\
\hline 2 & 35 & 12 & 18 & 9 & 49 & 123 \\
\hline 3 & 10 & 4 & 3 & 4 & 18 & 39 \\
\hline 4 & 36 & 21 & 24 & 10 & 73 & 164 \\
\hline 5 & 35 & 21 & 12 & 7 & 52 & 127 \\
\hline 6 & 29 & 13 & 4 & 8 & 32 & 86 \\
\hline 7 & 16 & 9 & 4 & 8 & 19 & 56 \\
\hline 8 & 7 & 6 & 6 & 5 & 15 & 39 \\
\hline 9 & 14 & 4 & 5 & 2 & 23 & 48 \\
\hline 10 & 22 & 3 & 3 & 5 & 27 & 60 \\
\hline & 229 & 101 & 83 & 67 & 334 & 814 \\
\hline
\end{tabular}

Sumber: Pendataan lapangan 2017
desa(Wibawa, 2018).

Urutan jumlah rumah terbanyak berada di RT 2, 4 dan 5. Bentuk rumah terbesar adalah Rongpyak atau kampung 334 rumah (41\%). Bentuk joglo pada urutan kedua sebagai bentuk bangunan terbanyak sebesar 229 rumah (28\%) dari jumlah bangunan yang ada.

\section{F. Analisis keberlanjutan Rumah Joglo}

\section{Gambar 5.}

Jumlah Bangunan dan KK pada setiap RT

\begin{tabular}{|c|c|c|c|c|}
\hline NO & $\begin{array}{c}\text { RUKUN } \\
\text { TETANG } \\
\text { GA (RT) }\end{array}$ & $\begin{array}{c}\text { RUKUN } \\
\text { WARGA } \\
\text { (RW) }\end{array}$ & JUMLAH KK & JUMLAH BANGUNAN \\
\hline 1 & 1 & \multirow[t]{4}{*}{1} & 37 & 72 \\
\hline 2 & 2 & & 64 & 123 \\
\hline 3 & 3 & & 19 & 39 \\
\hline 4 & 4 & & 81 & 164 \\
\hline 5 & 5 & \multirow[t]{6}{*}{2} & 71 & 127 \\
\hline 6 & 6 & & 42 & 86 \\
\hline 7 & 7 & & 30 & 56 \\
\hline 8 & 8 & & 23 & 39 \\
\hline 9 & 9 & & 26 & 48 \\
\hline 10 & 10 & & 29 & 60 \\
\hline JUMLAH & & & 422 & 814 \\
\hline
\end{tabular}

Sumber: Pendataan lapangan 2017

Di desa ini ratusan rumah joglo,

\section{Gambar 6. \\ Kompisisi bentuk bangunan}

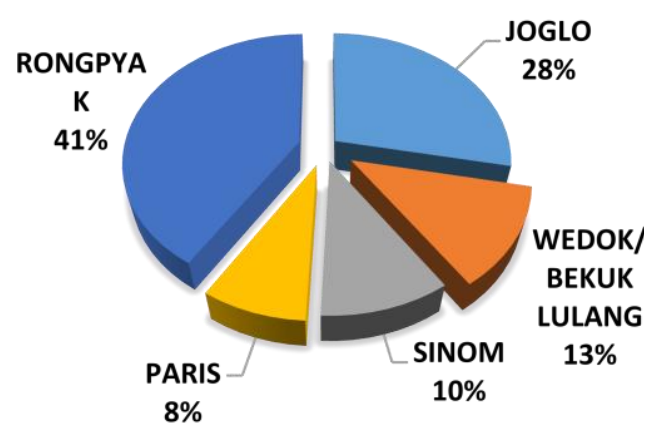

masih terus lestari, warga di desa ini bahkan tidak terlalu terpengaruh oleh kemajuan zaman yang seringkali mengagungkan rumah tembok. Informasi dari salah tokoh masyarakat bahwa tradisi turun temurun warganya yang selalu membuat joglo ketika membangun rumah baru.

Terlepas dari alasan biaya, teknis dan 
sosial yang ada, warga juga menginginkan agar desanya terus menjadi pelestari rumah joglo di Kabupaten Rembang. Saat ini masih terdapat beberapa rumah joglo yang sudah berumur ratusan tahun, meski rata-rata berusia puluhan tahun. Warga tidak malu dibilang kuno gara-gara enggan membangun rumah tembok dan memilih rumah joglo(Pondokrejo, 2019). Justru banyak warga dari kampung lain yang bangga dengan semangat warga desanya dalam melestarikan rumah budaya Jawa ini.

Keberadaan rumah-rumah joglo di Pondokrejo yang banyak mengalami pengaruh dalam penggunaan material dan tawaran untuk menjual, namun dalam kenyataannya eksistensi dan pertumbuhannya masih tetap terjaga sampai saat ini. Terlepas dari besar dan kecilnya pengaruh luar yang masuk dalam kebudayaan, ternyata keberadaan dan eksistensi rumah tinggal joglo di Pondokrejo masih eksis dan mampu bertumbuh dari tahun ke tahunnya. Berdasarkan data lama tahun 2010, dalam satu kawasan desa dihuni oleh 346 KK tersebut terdapat 217 rumah Joglo yang sebagian besar telah berumur ratusan tahun. Jumlah ini bila dibandingkan dengan data terbaru tahun 2017 terdapat jumlah rumah sebanyak 848 dengan penambahan jumlah bangunan joglo sebanyak 12 rumah joglo menjadi 229 rumah joglo. Suatu angka pertumbuhan yang mampu menunjukkan keberadaan bangunan rumah joglo masih sangat kuat dan kental di dalam masyakatnya, sekaligus menunjukkan adanya warisan nilainilai sosial dan budaya yang masih terus berjalan dan lestari dalam kehidupan sehari-hari masyarakatnya.

\section{G. Analisis Faktor Pelestarian}

Salah satu model keberlanjutan adalah model empat pilar keberlanjutan (Hawkes and Work, 2001), dalam pendekatan ini memerlukan perspektif budaya dalam perencanaan kebijakan berkelanjutanmelalui cara-cara integrasi antar pilar-pilar dalam satu model. Kontribusi budaya pada mode ini mendasari semua kejadian sosial, ekonomi, dan perilaku manusia pada lingkungannya. Budaya menjadi pilar utama yang berperan melakukan sinergi dan integrasi di antara pilar sosial, pilar ekonomi, dan pilar lingkungan. Pada model ini, mengakuibahwa kesejahteraan manusia merupakan tujuan utama dalam proses keberlanjutan. Sedangkan kualitas hidup adalah gagasan mulia di datam upayameningkatkan keberadaban budaya, yang tercermin di dalam implementasi nilai-nilai, aspirasi, ekspresi, dialog, keragaman, kreativitas, pembaharuan, dan vitalitas kehidupan sehari-hari yang saling

Gambar 8. Model 4 pilar keberlanjutan

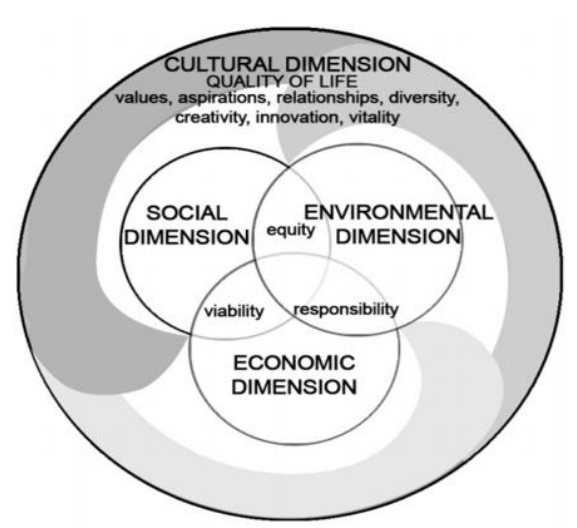

Sumber: Runnalls, 2006 dalam (Duxbury and Gillette, 2007)

terkait(Duxbury and Gillette, 2007).

Untuk mencapai keberlanjutan, masyarakat perlu mengintegrasikan kegiatan sosial ekonomi, dan lingkungan. Model empat pilar keberlanjutan, sehingga tidak ada tujuan tunggal di dalam pembangunan, atau hanya memenuhi kebutuhan sekelompok orang, atau fungsi sektoral yang tidak semestinya diutamakan atas fungsi yang lain. 
Dalam kampung joglo ini, keberadaan adat serta tradisi (budaya) bahwa rumah-rumah joglo merupakan puncak keindahan dan kebesaran rumah bagi masyarakatnya telah membentuk tradisi bahwa membangun rumah joglo telah dan selalu selalu menjadi keinginan dan cita-cita setiap keluarga. Bagi masyarakat kurang mampu, awalnya akan membangun rumah di bagian belakang dengan bentuk lain yang lebih murah (kampung/rongpyak/limasan), tapi bila telah mampu akan membangun rumah joglo di bagian terdepan. Budaya membangun joglo sudah sangat melekat di masyarakat dan telah menjadi tujuan masyarakat secara bersama, sehingga dapat menjadi dsar bagi keberlanjutan rumah joglo di kampung ini.

Dari informasi Bp. Sumarno menyebutkan bahwa terdapat spirit dari sebagian besar warga yang menginginkan agar rumah joglo tetap lestari. Dari pengalaman di lapangan, hanya untuk rumah yang sudah mendekati pelapukan atau rusah parah parah yang dijual, selebihnya masih dipertahankan. Buktinya, rumah yang berumur ratusan tahun, masih dapat ditemui sampai sekarang. Menurutnya, jumlah rumah joglo di desanya hampir selalu bertambah tiap tahun. Memang masih terdapat warga tergoda oleh para kolektor atau pemburu kayu jati untuk bahan meubel, namun jumlah mereka selalu tergantikan dengan selalu terbangunnya joglo-joglo baru setiap tahunnya.

Dari sisi ekonomi, bagunan rumah joglo dapat menjadi aset penting setiap keluarga yang dapat diwariskan kepada keturunannya. Rumah joglo menjadi aset yang dapat diperjualbelikan dengan nilai harga yang tetap cukup tinggi untuk menutup kebutuhan ekonominya.

Bila seatu keluarga belum mampu untuk membangun rumah joglo saat ini, maka mereka membuat rumah tipe "sinom" terlebih dahulu, kemudian setelah mampu maka atap tengahnya dapat dirubah menjadi bentuk joglo. Semakin tinggi dan besar rumah joglonya, maka akan semakin menunjukkan tingkat derajad keluarganya yang semakin tinggi pula. Bagi masyarakat yang mampu, maka mereka dapat memiliki dua joglo pada rumahnya.

Adanya aspek-aspek sosial kekerabatan bahawa bahwa setiap anak perempuan yang sudah menikah hampir selalu bisa dipastikan akan dibangunkan rumah joglo oleh orang tuanya merupakan salah satu aspek budaya yang mampu menjamin kelangsungan pertumbuhan rumah joglo di desa ini. Proses mendirikan rumah joglo sampai saat ini masih selalu dilaksanakan secara gotong royong, bahkan tradisi memindahkan rumah lama ke lokasi baru biasanya dilakukan secara bersama-sama diangkat tanpa membongkar konstruksi rumahnya (hanya atap genting yang diturunkan) masih tetap berjalan dan lestari sampai sekarang. Aspek sosial ini sangat mendukung bagi keberlanjutan eksistensi rumah joglo di Pondokrejo ini.

Dari aspek lingkungan, awalnya rumah-rumah joglo di Pondokrejo dibuat dengan kayu dari hutan belantara, bahkan dari kayu yang telah bertahun-tahun tertimbun tanah. Hal ini dapat dipahami karena kampung ini memang berada di sekitar hutan-hutan jati yang sangat terkenl kualitasnya pada masa lalu. Kini, warga tidak melulu mengandalkan kayu dari hutan karena sudah semakin menipis dan terbatas. Mereka memiliki cadangan hutan jati yang ditanam sendiri di lahan tegalan (Pondokrejo, 2019). Proses pergeseran ini menjadikan pembangunan joglo di dea ini tetap berlanjut. Orang tua selalu telah menanam dan menyiapakan tanamantanaman jati bagi anak-anaknya sejak 
dini, sehinggga bila telah tiba saatnya anaknya menikah, maka pohon-pohon jati tersebut telah siap ditebang dan dapat digunakan untuk membangunan rumah baru.

Di desa ini memiliki Perdes (peraturan desa) yang mengatur perlindungan dan keberlanjutan rumah joglo berusia tua. Peraturan itu mampu mengurangi penjualan joglo kuno yang sebenarnya dapat menjadi benda cagar budaya. Perdes No. 3 Tahun 2007 tentang Pelestarian dan Perlindungan Rumah Joglo tertanggal 20 November 2007 ini dibuat berdasarkan musyawarah warga bersama pemerintah desa. Salah satu pasalterpenting peraturan itu adalah melarang warga desa untuk menjual rumah joglo. Mereka yang menjual rumah joglo memang tidak dikenai sanksi, tetapi akan malu karena secara sosial melanggar peraturan yang telah dibuat dan disepakati secara bersama.

\section{KESIMPULAN}

Lingkungan permukiman joglo di Desa Pondokrejo ini merupakan permukiman joglo asli bagi budaya Jawa saat ini yang masih bertahan dan lestari dalam setting sosial budaya masyarakatnya yang aslinya. Suatu aset dan potensi yang sangat besar sebagai "museum alami" dalam upaya melestarikan artefak asli budaya jawa dalam rumah joglo dalam setting aslinya. Dominasi rumah berbentuk joglo di lingkungan permukiman ini merupakan kondisi yang sangat unik dan belum ditemykan di tempat lain.

Terdapat empat pilar keberlanjutan pembangunan yang dapat menjamin keberlanjutan pembangunan yaitu sosial, pilar ekonomi, dan pilar lingkungan. Dalam konsep ini budaya menjadi aspek penting yang mengintegrasikan semua pilarnya.Terdapat beberapa aspek yang mendukung pelestarian kampung ini sebagai berikut:

1. Secara budaya, bentuk bangunan joglo memiliki makna dan tradisi yang sangat kuat bagi masyarakatnya, sehingga secara tururn-menurun pembangunan rumah joglo masih berlanjut sampai sekarang.

2. Secara ekonomi, bangunan benbetuk joglo masih merupakan simbol stratifikasi masyarakat secara ekonomi. Semakin besar dan tinggi rumah joglonya, maka semakin tinggi status sosial ekonomi pemiliknya. Bangunan joglo dapat menjadi aset ekonomi yang dapat diwariskan dan dijual belikan dengan harga yang tetap tinggi, sehingga dapat menjadi investasi atau tabungan bagi warga masyarakat yang memilikinya.

3. Secara sosial, terdapat tradisi bahwa selama beberapa waktu sesudah mereka menikah, lambatlaun mereka akan menempati rumah mereka sendiri yang dibangun oleh orang tua isteri di halaman rumahnya juga. Apabila halaman rumah terlalu sempit untuk mendirikan rumah yang tepisah, maka seringkali tempat tinggal yang dibangun menempel pada rumah induk dengan cara menyambungkan atapnya (Koentjaraningrat, 1984).Sistem gotong-royong dalam membangun rumah masih berjalan sampai sekarang dalam setiap mendirikan atau memindahkan rumah tinggal.

4. Dari aspek lingkungan, terdapat proses adaptasi secara berkelanjutan terkait kebutuhan bahan baku kayu jati untuk membangun rumah joglo. Bila awalnya warga mengandalkan kayu dari hutan, maka seriring perkembangannya, masyarakat beralih dengan menggunakan 
kayu-kayu yang ditanam di sekitar lingkungan permukimannya. Masyarakat telah menanam pohon jati sejak anak-anak mereka masih kecil, diharapkan bila mereka sudah menikah, maka pohon-pohon jati yang telah dipersiapkan sudah siap ditebang untuk membangunakan rumah bagi anak-anaknya.

Walaupun dari aspek pilar kebelanjutan telah dapat terlihat ekesistensinya, namu tetap perlu peran dan partisipasi semua pihak agar dapat lebih mendorong dan membantu upaya dan kesadaran mesyarakat Desa Pondokrejo untuk selalu setia dengan tradisi dan budaya membangun dan menggunakan rumah joglonya. Apresiasi yang sangat besar harus dapat diberikan kepada mereka yang sampai saat ini masih tetap melestarikan rumah-rumah joglonya di antara gencarnya gempuran teknologi bahan bangunan yang lebih murah dalam era globalisasi ini.

\section{DAFTAR PUSTAKA}

Duxbury, N. and Gillette, E. (2007) 'Culture as a Key Dimension of Sustainability', (1).

Hawkes, B. Y. J. O. N. and Work, D. T. N. E. T. (2001) THE FOURTH PILLAR OF SUSTAINABILITY. Australia: dbooks.

Koentjaraningrat (1984) Kebudayaan Jawa. Seri Etnog. Jakarta.

Pitana, T. S. (2013) 'Arsitektur Joglo Ekspresi Ruang Kesadaran Manusia Jawa, Kearifan Lokal Jawa, Dan Sarana Komunikasi Visual', pp. 1-12. Available at: https://www.scribd.com/doc/135 083487/Filosofi-Joglo.

Pondokrejo, D. (2019) CERITA MBAH SHOIM TENTANG PELESTARI KAMPUNG JOGLO DI DESA
PONDOKREJO BULU REMBANG JAWA TENGAH. Available at: http://pondokrejorembang.sideka.id/cerita-mbahshoim-tentang-pelestarikampung-joglo-di-desapondokrejo-bulu-rembang-jawatengah/.

Susilo, G. A. (2010) 'PERANAN ARSITEKTUR TRADISIONAL JAWA DALAM PEMBANGUNAN BERKELANJUTAN ( STUDI KASUS ARSITEKTUR JOGLO PONOROGO )', pp. 1-8.

Wibawa, B. A. (2018) 'Pondokrejo, Kampung Joglo yang Lestari.', 23 December, p. 14. Available at: http://epaper.suaramerdeka.com/e paper/detail/2018/12/23/14. 